\title{
IMPLICACIONES DE LA ÉTICA PARA LOS TERAPEUTAS OCUPACIONALES
}

\author{
Carolina López Díaz, T.O* \\ Andrea María Perozo Molina, T.O.**
}

\begin{abstract}
"Sócrates pensaba que había unas reglas básicas y etemas para lo que es bueno y lo que es malo: mediante nuestra razón podemos, todos los seres humanos, llegar a conocer esas normas inmutables, pues precisamente la razón de los seres humanos es algo eterno e inmutable".
\end{abstract}

Jostein Goorden. "El mundo de Sofia".

La edad moderna ha traído consigo el confort, los computadores, las tarjetas de crédito, los avances científicos, las telecomunicaciones, la rapidez, la velocidad de la información, la facilidad de las cosas a corto plazo, el ya, el momento y el ahora.

Es allí donde el hombre debe tomar decisiones igualmente rápidas sobre cada una de las situaciones de su vida: debe tomar un bus, manejar su dinero, educarse profesionalmente, competir laboralmente, relacionarse con los demás, formar y fortalecer una familia hasta comprometerse con su calidad de vida. Se empieza a decidir entre acciones buenas y acciones malas, no solo en el ámbito profesional, sino que trascienden al hacer y actuar personal en donde ya no solo se toma decisiones acerca de cosas, objetos o elementos, sino de personas que merecen ser respetadas en la atención que se les preste.

En lo profesional el respeto y consideración es el producto de múltiples variables: los valores personales, los principios morales, los deberes, los compromisos profesionales y la solidez de la formación personal, todo lo que puede ser resumido en una palabra "la ética".

El presente artículo reflexiona sobre algunos conceptos que desde la ética, deben estar manejando los terapeutas ocupacionales. Específicamente se contemplan al-

* T.O. Universidad Nacional de Colombia.

** T.O. Universidad Nacional de Colombia. 
gunos aspectos relacionados con la ética en general, con el código de ética colombiano y sus limitaciones. Que el terapeuta ocupacional se apropie de estos temas es particularmente urgente. En momentos de la grave crisis de valores por la que atraviesa la nación colombiana, en la que cada profesional desde su perspectiva actúe de manera ética colaborando en la construcción de una nueva sociedad.

La ética puede ser definida de varias maneras. De acuerdo a Purtilo (1994) es "el estudio y análisis de la moral". Según Sánchez (1995) "la ética es la disciplina que se ocupa de la moral; de algo que compete a los actos humanos exclusivamente y que los califica como buenos o malos a condición de que ellos sean libres, voluntarios y conscientes".

Entonces se puede afirmar que la ética es la ciencia que estudia la moral; es decir que la relaciona con el concepto de lo bueno y lo malo, de lo que se debe o no se debe hacer, de acuerdo a las diferentes sociedades y sus costumbres, pues son ellas quienes determinan el comportamiento de los individuos que las conforman. Lo anterior permite deducir que la moral no es permanente, debido a que cambia de una época a otra, no es lo mismo hablar hace un siglo del cumplimiento de la palabra de una persona, cuando los hombres se enfrentaban a duelos porque ante todo lo que se decía se cumplía y no como sucede ahora, donde continuamente se asiste a las falsas promesas y al incumplimiento.

Se ha perdido o transgredido los valores morales: la solidaridad, la honestidad, la justicia, el cumplimiento de la palabra, la responsabilidad, de diligencia, el respeto; porque viene transmitiéndose, generación en generación, unos valores donde predomina el interés personal, el triunfo fácil, el beneficio propio y la ignorancia o descalificación de los problemas de los demás para hacer valer tan solo los propios. Persiste la idea equivocada de que todo fin justifica los medios; lo fácil es más rápido y da mejores resultados; se práctica la ley del menor esfuerzo, de la trampa y el soborno, que impide actuar en pro de los beneficios comunes y conducen a la mediocridad.

Estos valores, que aquí se entiende como antivalores, se ven y se viven social y profesionalmente. A nivel social se expresan en la impuntualidad, las excusas, el aprovecharse del turno del otro, pasar el semáforo en rojo, la burla, la crítica destructiva, el deterioro de las áreas comunitarias, el tráfico de influencias, la violación a los derechos humanos, el robo material y también intelectual. Basta mirar 
alrededor para encontrar muchos más ejemplos que se cometen y cometemos y que la sociedad y la familia aceptan y elogian con un falso concepto de inteligencia y vivacidad, o que implícitamente aprueban al mantener silencio o no asumir una posición de franco rechazo.

Estos antivalores permean a nuestra formación universitaria y profesional. No es extraño ver un estudiante copiando un examen y observar la complicidad de los demás para callar y no denunciar públicamente el acto ilícito. Se tiene la idea errónea que esta conducta es inocua o que el fin de obtener una buena nota justifica los medios fraudulentos, sin comprender que de podrán extender a aspectos más complejos y trascendentes de la vida.

Otros antivadores presentes durante la vida universitaria son la impuntualidad para reuniones y entregas de trabajos que atentan contra el respeto del tiempo de las demás personas; la mediocridad no sólo en los estándares de calidad de los trabajos, sino en que la mayoría de los casos son copias textuales de otros libros careciendo de análisis y aporte personal. Por otra parte es común que el profesional en formación se conforme con el conocimiento impartido por el docente, como muestra del poco interés y compromiso con la búsqueda de estrategias que enriquezcan su aprendizaje.

Esta conducta de antivalores continúa en la vida profesional, convirtiéndose en un factor de preocupación y gravedad, pues esta acción afecta o beneficia directamente a personas y grupos. Por ejemplo, la desactualización del conocimiento profesional; la inasistencia a conferencias; la preferencia o rechazo por ciertos clientes/usuarios debido a intereses personales, la falta de planeación o duración de las intervenciones; la baja calidad de las actividades; la carencia de confort en el área destinada a terapia ocupacional; la poca divúlgación y el desinterés por investigación en el avance del conocimiento; el pobre análisis y argumentación de las acciones profesionales.

La ética también involucra el cumplimiento de los deberes y la exigencia de los derechos. El deber es hacer aquello que la sociedad ha impuesto en bien de los intereses colectivos y particulares; la persona es buena y actúa correctamente cuando cumple con las tareas y deberes que debe hacer. Purtilo establece cuatro deberes que pueden relacionarse con la vida del terapeuta ocupacional. 
El primero es el "no maleficio" es decir no hacer daño a otros, en este caso esto debe reflejarse en toda intervención terapéutica considerando todos los factores de la persona, de la actividad, del medio ambiente que puede interferir desfavorablemente en el progreso del usuario/cliente, con otros profesionales y con la profesión. Por ejemplo, con usuario/cliente, el "no maleficio" implica: cumplir con las citas y tiempo previsto para las intervenciones; aplicar las pruebas acordes al caso particular; utilizar los medios y las modalidades adecuadas, comunicar al usuario/cliente en forma clara y veraz los progresos, limitaciones y resultados de la atención; y establecer tarifas de costos por tratamiento.

El "no maleficio" con los demás profesionales se evidencia en algunos comportamientos éticos como'reconocer los límites de los campos de acción profesional que evite la incursión en áreas que por objeto de estudio no corresponde a los terapeutas ocupacionales y participar en grupos interdisciplinarios manteniendo una posición clara como terapeuta ocupacional ante la situación a resolver.

Y con la profesión, el "no maleficio" se traduce en: la calidad del trabajo profesional que promueve el reconocimiento en cualquier área, la solidaridad profesional, la divulgación de los logros alcanzados en las áreas nuevas, y tradicionales, y el logro y aceptación de la remuneración que corresponda al tipo de características de la labor profesional efectuada

El segundo deber se relaciona con el "beneficio" es decir el mejoramiento de la calidad de vida de nuestros usuarios/clientes, y de la sociedad en que se desenvuelve el terapeuta ocupacional. Como ejemplo del beneficio hacia los usuarios, se ve expresado en la posibilidad de reinserción de un discapacitado físico en el mundo laboral lo que repercutirá en la satisfacción de necesidades personales, sociales y ocupacionales, adecuar espacios físicos que ofrezcan confort a los usuarios y favorecer la aceptación de la familia hacia la situación de la persona discapacitada. Hacia la sociedad, el beneficio se expresa en la medida en que se desarrollan proyectos que den soluciones a sus necesidades ocupacionales.

El tercero es la "veracidad" lo que se relaciona con poder expresar acertada y sinceramente todo lo relacionado con la evaluación y tratamiento de un usuario/ cliente, es decir poderle comunicar su pronóstico, sus posibilidades de recuperación, los objetivos de tratamiento, la duración, costos, metas y los logros progresivos que se vayan obteniendo. 
Finalmente el último valor es la "fidelidad" que consiste en confiar en la actuación de las personas, en la vida profesional. Ser fiel a la terapia ocupacional significa considerarla como una profesión que esta en posibilidades de abordar la ocupación, al hombre y al medio ambiente; actuar de acuerdo a sus principios; evaluar sus alcances y sus limitaciones y comprometerse al avance y consolidación dentro de la sociedad.

Lo anterior es solo una muestra de los que en la vida cotidiana, personal y profesional puede cambiar, se debe dejar a un lado el facilismo, el camino rápido, pensar que la actuación cotidiana de cada persona tiene unas consecuencias a largo plazo, y aquí se está de acuerdo con Sanjinés cuando menciona "...no hay atajos hacia el desarrollo del individuo, su preparación, su capacitación y el desarrollo de sus valores...*

La Sociedad colombiana requiere una transformación en su escala de valores, una actitud de rechazo a los antivalores, recuperar la credibilidad en cada individuo y esto solo se logra en primera instancia por medio de una labor de fortalecimiento de cosas buenas y en segunda instancia de la educación, pues allí es donde se vitalizan y cobran utilidad cada uno de estos aspectos. 


\section{BIBLIOGRAFÍA}

ASOCIACIÓN COLOMBIANA DE TERAPIA OCUPACIONAL. Módulo de Orientación Profesional para Terapeutas Ocupacionales. Código de Ética. Santa Fe de Bogotá. Autor. 1994.

GARDERN, J. El Mundo de Sofía. Madrid-España. Ciruela Norma. 1994

HORTTA, E. y RODRÍGUEZ, V. Ética general. Santa Fe de Bogotá. Editorial Presencia. 1994.

LLANO ESCOBAR A. "Un alto en el camino, qué son valores morales". En: El Tiempo. Santa Fe de Bogotá. (10 de marzo de 1996).

PURTILO, B. Ethics in professional practice. In American Occupactional Therapy Association (Ed.). The AOTA Practice symposium 1989. Pp 10-12 Rockville, MD: Auto.r

SÁNCHEZ TORRES, F. Ética méúica. Santa Fe de Bogotá. Giro editores. 1995.

SANJINEZ ORJUELA, A. "Reingenieria del Colombiano. Atajos de la Malicia Indígena". En: Lecturas dominicales. El Tiempo. Santa Fe de Bogotá (10 de marzo de 1996). 